\title{
A NOÇÃO DE DIREITO NO PROCESSO CIVILIZATÓRIO: UMA RELACĈ̃O DE PODER E NEGAÇÃO DO CONTRATO SOCIAL DE ROUSSEAU
}

\author{
Rodrigo Rage Ferro* \\ Henrique Garbellini Carnio**
}

SUMÁRIO: Introdução; 2 Noção de direito no processo civilizatório: negação da teoria contratualista de Rousseau; 2.1 A Teoria contratualista de Rousseau; 2.2 Crítica ao contratualismo de Rousseau em Freud, Nietzsche e Kelsen; 3 Noção de direito como relação de poder e força; 4 Conclusão; Referências.

RESUMO: O problema que se perscrute nesse artigo é refletir se a base da legitimidade estatal residiria na figura de um contrato social, como explicita a famosa Teoria do Contrato Social de Rousseau. Tal assertiva, contudo, entra em conflito com o fato de o direito, como uma criação humana, ser fruto de um processo civilizatório marcado pela barbárie e pelo castigo, portanto por critérios totalitários, e com a própria concepção normativa que está no próprio homem e que não permite que o direito se mantenha livre dessa influência. Isso vai em direção oposta ao surgimento de um Estado com base em um acordo voluntário de indivíduos, o que, per se, justifica cientificamente esta análise pormenorizada e onde reside sua relevância social. Cabe este artigo, como principal objetivo, baseado em um processo metodológico e sistemático de investigação com contribuições teóricas de Freud, Nietzsche e Kelsen, mostrar que a noção de direito promoveu o processo civilizatório com base em relações de poder, domínio e força de forma que não se coaduna com uma gênese da força normativa com base na teoria do contrato social de Rousseau. Chegou-se a esse resultado, com base em uma visão histórico-pragmática, a partir da reflexão desses filósofos sobre a história da humanidade e o próprio entendimento dos autores desse artigo sobre a relação entre a noção de direito e a evolução do processo civilizatório.

PALAVRAS-CHAVE: Noção de direito; Processo civilizatório; Relação de poder;

\footnotetext{
Doutorando da Faculdade Autônoma de Direito de São Paulo (FADISP) e Mestre pela Escola Paulista de Direito (EPD). Brasil. 
Contrato social de Rousseau.

\title{
LAW WITHIN THE CIVILIZING PROCESS: THE RELATIONSHIP BET WEEN POWER AND THE DENIAL OF ROUSSEAU'S SOCIAL CONTRACT
}

\begin{abstract}
Current discussion investigates whether state legitimacy is based on the social contract forwarded by the Theory of Social Contract introduced by Rousseau. The statement contests the fact that man-made law is the result of a civilizing process marked by savagery and punishment, or rather, by totalitarian criteria, and that the normative concept in humans which does not permit that rights are relieved from such an influence. The above is directly opposite the rise of the State based on a voluntary agreement of the people, which scientifically justifies per se the detailed analysis and its social relevance. The paper, based on the methodological and systematic process of investigation, with theoretical contributions by Freud, Nietzsche and Kelsen, demonstrates that law triggered the civilizing process through power relationships, dominion and force, which fails to comply with the genesis of normative force based on Rousseau's social contract. These results were grounded on historical and pragmatic bases discussed by these philosophers on the history of humanity and on their interpretation on the relationship between law and the evolution of the civilizing process
\end{abstract}

KEY WORDS: Law; Civilizing process; Power relationship; Rousseau's social contract.

\section{LA NOCIÓN DE DERECHO EN EL PROCESO CIVILIZATORIO: UNA RELACIÓN DE PODER Y NEGACIÓN DEL CONTRATO SOCIAL DE ROUSSEAU}

RESUMEN: El problema que se escrutan en ese artículo es reflexionar si la base de la legitimidad estatal residiría en la figura de un contrato social, como explicita la famosa Teoría del Contrato Social de Rousseau. Tal asertiva, sin embargo, entra en conflicto con el hecho de el derecho, como una creación humana, ser fruto de un proceso civilizatorio marcado por la barbarie y por el castigo, por lo tanto, por criterios totalitarios, y con la propia concepción normativa que está en el propio hombre y que no permite que el derecho se mantenga libre de esa influencia. Eso va en dirección contraria al surgimiento de un Estado con base en un acuerdo voluntario 
de individuos, lo que, per se, justifica científicamente este análisis pormenorizada y en que reside su relevancia social. Cabe este artículo, como principal objetivo, basado en un proceso metodológico y sistemático de investigación con contribuciones teóricas de Freud, Nietzsche y Kelsen, mostrar que la noción de derecho promovió el proceso civilizatorio con base en relaciones de poder, dominio y fuerza de forma que no se coaduna con una génesis de la fuerza normativa con base en la teoría del contrato social de Rousseau. Se llegó a ese resultado, con base en una visión histórico-pragmática, a partir de la reflexión de esos filósofos sobre la historia de la humanidad y el propio entendimiento de los autores de ese artículo sobre la relación entre la noción de derecho y la evolución del proceso civilizatorio.

PALABRAS CLAVE: Noción de derecho; Proceso civilizatorio; Relación de poder; Contrato social de Rousseau.

\section{INTRODUÇÃO}

Tem-se desenvolvido, no pensamento jurídico-político do Ocidente, uma série de concepções referentes ao fundamento de legitimidade estatal e aos fundamentos do direito, muitas vezes, caracterizado como algo místico: fundamento místico da autoridade da lei ${ }^{03}$.

À primeira vista, parece lógico haver na lei, indissociavelmente, um elemento de força e mesmo de violência, uma vez que é largamente conhecida a fórmula do Estado como detentor do monopólio de uso da força ${ }^{04}$. Contudo, tradicionalmente, muito se discute se a base dessa legitimidade estatal residiria na figura de um contrato social, isto é, em um pacto firmado em bases racionais e voluntárias em "que os cidadãos, em condições justas, abrem mão de seus direitos individuais e consentem com o poder de uma autoridade na qual depositam confiança" ${ }^{05}$ de forma que a gênese do Estado e da sociedade estariam não nas relações de dominação, poder e uso da força, mas em um acordo de vontades de indivíduos livres em seu estado originário.

Diante disso, o problema que se perscrute nesse artigo é refletir se a base

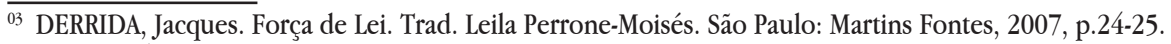

${ }^{04}$ MARANHÃO, Bernardo Costa Couto de Albuquerque. Força de lei e fundamento da autoridade em Freud. XVIII Encontro Nacional do CONPEDI. 2009, p.3304-3319. Disponível em: < http://www.publicadireito.com. br/conpedi/anais/36/02_1108.pdf>. Acesso em: 20.set.2017, p.3309.

${ }^{05}$ VILALBA, Hélio Garone. O contrato social de Jean-Jacques Rousseau: uma análise para além dos conceitos. Revista eletrônica Filogênese.v.6. n.2. Marília, 2013, p.63-76. Disponível em: <http://www.marilia.unesp.br/ Home/RevistasEletronicas/FILOGENESE/heliovilalba.pdf>. Acesso em: 19. set. 2017, p.63.
} 
da legitimidade estatal residiria na figura de um contrato social, como explicita a famosa Teoria do Contrato Social de Rousseau. Justifica-se a relevância de tal análise, uma vez que tal assertiva entra em conflito com o fato de o direito, como uma criação humana, ser fruto de um processo civilizatório marcado pela barbárie e pelo castigo, portanto por critérios totalitários, e com a própria concepção normativa que está no próprio homem e que não permite que o direito se mantenha livre dessa influência. Portanto, o objetivo deste artigo é mostrar que a noção de direito ao longo do processo civilizatório é baseada em relações de poder, domínio e força de forma que não se coaduna com a teoria do contrato social de Rousseau marcada pela explicação da gênese do Estado por um acordo convencional entre os indivíduos na busca de alcançar a liberdade civil em detrimento da liberdade do estado da natureza.

Como auxílio para a reflexão acerca do papel desempenhado pelo direito, a base de legitimidade estatal e o caráter violento do direito no ato de fundação, ou melhor, a sua noção ao longo do processo civilizatório, foi trazida a lume, neste artigo, contribuições teóricas de grandes pensadores: Freud, Nietzsche e Kelsen.

De fato, baseado em um processo metodológico e sistemático de investigação com contribuições teóricas desses filósofos, mostrou-se que a noção de direito promoveu o processo civilizatório com base em relações de poder, domínio e força de forma que não se coaduna com uma gênese da força normativa com base na teoria do contrato social de Rousseau.

\section{NOÇÃO DE DIREITO NO PROCESSO CIVILIZATÓRIO: NEGAÇÃO DA TEORIA CONTRATUALISTA DE ROUSSEAU}

\subsection{A TEORIA CONTRATUALISTA DE ROUSSEAU}

A teoria do Contrato Social é uma das principais referências teóricas do Estado moderno surgida no século XVII e desenvolvida, principalmente, por Jean-Jacques Rousseau (1712-1778) ${ }^{06}$. Cria-se um mito de origem para o Estado,

${ }^{06}$ ROUSSEAU, Jean-Jacques. Do Contrato Social. Trad. Lourdes Santos Machado. São Paulo: Nova Cultural, 1997. 
justificando sua legitimidade e estabelecendo limites para o poder soberano ${ }^{07}$.

Em sua teorização, o Estado funda-se a partir de um contrato, isto é, um pacto realizado entre indivíduos livres que viviam em um "estado de natureza" conforme suas forças e vontades, submetidos unicamente aos limites que se podiam impor uns aos outros por meio da força física. Por razões diversas - ausência de regras, necessidade ou esperança ${ }^{08}$ - os indivíduos, como partes contratantes em condição de igualdade, concordam em fazer um pacto de forma a haver uma colaboração maior entre si e a uma limitação recíproca de suas forças, abrindo mão de uma parte dos direitos de que gozavam no estado de natureza para assim se proteger contra a tirania de seus pares e em nome do bem comum. Saem da condição de estado de natureza e adentram em um estado civil, marcado pelo pacto social ou contrato, que segundo a teoria é a base da origem do Estado. Este, na figura do soberano, passa a deter a exclusividade no uso da violência ${ }^{09} \mathrm{e}$ tem o dever de proteger os cidadãos ${ }^{10}$. Ademais, parte-se da suposição de um ato de vontade envolvido na adesão de cada indivíduo ao pacto social, como um ato jurídico voluntário em vez de coercitivo.

Segundo Rousseau, o pacto social visa: "encontrar uma forma de associação que defenda e proteja a pessoa e os bens de cada associado com toda a força comum, e pela qual cada um, unindo-se a todos, só obedeça contudo a si mesmo, permanecendo assim tão livre quanto antes" ${ }^{11}$.

É relevante que se diga que para Rousseau, o homem, em seu estado da natureza, é considerado como um "bom selvagem" e que é a sociedade a corruptora de sua natureza ${ }^{12}$. O contrato social constitui o fim desse estado, pondo fim às lutas individuais pela autopreservação e proporcionando ao homem ter uma consciência de elementos morais dentro do seio de uma sociedade, além de poder constituir

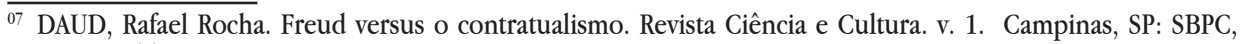
2015, p. 46.

${ }^{08}$ ESLABÃO, Daniel da Rosa. Nietzsche e o contratualismo. I Congresso Internacional de Filosofia Moral e Política. Pelotas, 2009. Disponível em: < http://cifmp.ufpel.edu.br/anais/1/cdrom/mesas/mesa7/03.pdf > . Acesso em: 21.set.2017, p.2.

${ }_{09}^{09}$ DAUD, Rafael Rocha. Freud versus o contratualismo. Revista Ciência e Cultura. v. 1. Campinas, SP: SBPC, 2015, p. 46.

${ }^{10}$ VILALBA, Hélio Garone. O contrato social de Jean-Jacques Rousseau: uma análise para além dos conceitos. Revista eletrônica Filogênese.v.6. n.2. Marília, 2013, p.63-76. Disponível em: < http://www.marilia.unesp.br/ Home/RevistasEletronicas/FILOGENESE/heliovilalba.pdf > . Acesso em: 19.set.2017, p.63.

${ }^{11}$ ROUSSEAU, Jean-Jacques. Do Contrato Social. Trad. Lourdes Santos Machado. São Paulo: Nova Cultural, 1997, p.69.

${ }^{12}$ ESLABÃO, Daniel da Rosa. Nietzsche e o contratualismo. I Congresso Internacional de Filosofia Moral e Política. Pelotas, 2009. Disponível em: < http://cifmp.ufpel.edu.br/anais/1/cdrom/mesas/mesa7/03.pdf > . Acesso em: 21.set.2017, p.2.
} 
uma organização política, requisito da necessidade social humana ${ }^{13}$. Diante disso, as ações individuais passariam a ter de respeitar as leis que levam em consideração à vontade geral e em nome do bem comum ${ }^{14}$.

Ao perscrutar sobre o mito da gênese do Estado a partir do contrato social como um apelo ao estado da natureza, perde-se todo o aspecto histórico de sua formação e se considera como condição eterna e fatal o que não é senão uma etapa no desenvolvimento da sociedade, justificando uma soberania estatal a partir de uma ruptura abrupta entre o estado da natureza e o estado civil. Descreve-se uma condição humana abstratamente construída "ao invés de lançá-la adiante como meta ou utopia a ser alcançada, [...] esquecendo-se do caráter hipotético dessa construção e a tomando como natural: justificam as condições sociais atuais no que diz respeito às normas" ${ }^{15}$. De fato, de acordo com o contratualismo, "os fins de uma pessoa são formados antes ou independentemente da sociedade"16.

Nesse arrimo, simbolicamente a cultura e a teoria de formação da ordem jurídica abstratamente falando, a partir de um acordo de vontades, estabelecida com base no contrato social dos indivíduos, transmitem-se ao longo das gerações, ou seja, parece carregar certa positividade que é transmitida no processo civilizatório, ao modo de uma espécie de "direito natural" ou na perspectiva freudiana como um verdadeiro Totem ${ }^{17}$.

Paradoxalmente, é um fato que a nossa capacidade como indivíduos é "o produto de uma longa história e pré-história social" de modo que seus objetivos ou valores são socialmente constituídos ${ }^{18}$. Portanto, é nesse contraponto que ideias trazidas por Freud, Nietzsche e Kelsen podem ajudar a desmitificar esse fundamento mítico da autoridade da lei e compreender que a noção de direito como relação de poder é apenas uma extensão da sociedade.

\subsection{CRÍTICA AO CONTRATUALISMO DE ROUSSEAU EM FREUD, NIETZSCHE E} KELSEN

\footnotetext{
${ }^{13}$ VILALBA, Hélio Garone. op. cit., p.66.

${ }^{14}$ VILALBA, Hélio Garone. op cit., p.73.

${ }^{15}$ DAUD, Rafael Rocha. Freud versus o contratualismo. Revista Ciência e Cultura. v. 1. Campinas, SP: SBPC, 2015, p. 47.

${ }^{16}$ SIEMENS, Herman. Nietzsche e a sociofisiologia do eu. Cadernos Nietzsche (online). v.37. n.1. São Paulo, 2016, p.185-218. Disponível em: < http://www.scielo.br/pdf/cniet/v37n1/2316-8242-cniet-37-01-00185.pdf>. Acesso em: 21.set.2017, p.186.

${ }^{17}$ FREUD, Sigmund. Totem e tabu. E.S.B. XIII. Rio de Janeiro: Imago, 1978.

${ }^{18}$ SIEMENS, Herman. op cit., p.187.
} 
Freud em seus escritos sobre a cultura, especialmente em "Totem e tabu" ${ }^{19}$, por meio do mito da horda primitiva e se valendo dos pressupostos teóricos da psicanálise, tenta relatar a gênese da vida civilizada e como se originaram as suas principais realizações que definem a cultura, como, por exemplo, o direito.

Dissonante do tradicional pensamento clássico contratualista de Rousseau, onde há a prevalência do acordo discursivo, presumindo que "no princípio, era o verbo", Freud parte de uma premissa divergente, asseverando que "no princípio, era o ato", portanto, a convenção fundadora do direito é precedida de um gesto de força e até mesmo de um ato de violência ${ }^{20}$. Entre as consequências desta pressuposição é de que: "a) a força é um elemento constitutivo e indissociável do direito; b) a legalidade, por isso mesmo, contém já em sua origem, de forma latente, o risco da tirania" ${ }^{21}$.

Nessa toada, assim afirma Freud em uma correspondência trocada com Einstein, datada de 1933, intitulada "Por que a guerra?": "[...] estaremos fazendo um cálculo errado se desprezarmos o fato de que a lei, originalmente, era força bruta e que, mesmo hoje, não pode prescindir do apoio da violência" ${ }^{22}$.

Na versão freudiana, diferente de Rousseau, a passagem do estado conflitivo de natureza ao estado civilizado não constitui uma garantia de pacífica estabilidade. Em virtude da ambivalência dos afetos e, principalmente, quando estão ausentes as forças anímicas que inibem as pulsões de destruição e agressividade, corre-se o risco de ruptura da ordem civilizada e manifestação da barbárie inerente e mantida latente no indivíduo, não respeitando o semelhante, mas o tornando objeto de gozo, uso e abuso ${ }^{23,24}$

Também é relevante que se obtempere que a limitação da vida pulsional imposta pela civilização por meio da força da lei, como uma componente nuclear do tenso jogo de forças pulsionais entre o desejo e a proibição, ao mesmo tempo em que é fonte de insatisfação e sofrimento para o ser humano, impede a eclosão desmedida do gozo destrutivo ${ }^{25,26}$. De fato, a culpa e a obediência às instituições

\footnotetext{
${ }_{19}$ FREUD, Sigmund. op cit., 1978.

${ }^{20}$ MARANHÃO, Bernardo Costa Couto de Albuquerque. Força de lei e fundamento da autoridade em Freud. XVIII Encontro Nacional do CONPEDI. 2009, p.3304-3319. Disponível em: < http://www.publicadireito.com. br/conpedi/anais/36/02_1108.pdf > . Acesso em: 20.set.2017, p.3308.

${ }^{21}$ Ibidem.

${ }^{22}$ FREUD, Sigmund. Por que a guerra?, E.S.B. XXII. Rio de Janeiro: Imago, 1978, p.251.

${ }^{23}$ MARANHÃO, op cit., p. 3310.

${ }^{24}$ FREUD, Sigmund. Psicologia das massas e análise do eu. E.S.B. XVIII. Rio de Janeiro: Imago, 1978.

${ }^{25}$ MARANHÂO, op. cit., p. 3310.

${ }^{26}$ FREUD, Sigmund. O mal-estar na civilização. E.S.B. XXI. Rio de Janeiro: Imago, 1978.
} 
e à ordem jurídica deixam latente o ódio e a hostilidade contra as instituições da cultura.

Outrossim, é importante que se explicite com base no escólio de Freud, que há um verdadeiro fundamento místico na autoridade da lei, de maneira que a manobra jurídica dos Estados inventados pela civilização está fundada sobre um Totem ${ }^{27}$. Nas palavras de Derrida: "[...] o discurso encontra ali o seu limite: nele mesmo, em seu próprio poder performativo. É o que proponho aqui chamar, deslocando um pouco e generalizando a estrutura, o místico" 28.

Manifestando uma descrença nas verdades tradicionais, Nietzsche também, na sua dissertação segunda da obra "Genealogia da Moral" ${ }^{29}$, combate a teoria contratualista de Rousseau. Opõe suas concepções acerca da origem do Estado a partir de um pacto ou pacífico acordo de vontades ${ }^{30}$. Na "Genealogia da Moral", dissertação segunda, $\S 17$, assim propala o autor ressaltando que a origem do Estado e a própria legitimidade do direito residem na violência e na força e não em um contrato social.

[...] a inserção de uma população sem normas e sem freios numa forma estável, assim como tivera início, foi levada a termo somente com atos de violência - que o mais antigo Estado, em consequência, apareceu como uma terrível tirania, uma máquina esmagadora e implacável, e assim prosseguiu seu trabalho, até que tal matéria -prima humana e semianimal ficaram não só amassada e maleável, mas também dotada de uma forma. Utilizei a palavra "Estado": está claro a que me refiro - algum bando de bestas louras, uma raça de conquistadores e senhores, que organizada guerreiramente e com força para organizar, sem hesitação lança suas garras terríveis sobre uma população talvez imensamente superior em número, mas ainda informe e nômade. Deste modo começa a existir o Estado na terra: penso haver-se acabado aquele sentimentalismo que o fazia começar com um contrato ${ }^{31}$.

A filosofia contratualista, denunciada por Nietzsche, como uma mera ficção teórica, serviu de base para uma fundamentação fantasiosa que se estende até hoje. Na "Genealogia da Moral" e em outros textos, apresenta uma trajetória

\footnotetext{
${ }^{27}$ LEGENDRE, Pierre. De la societé comme Texte: Linéaments d'une Anthropologie Dogmatique. Paris: Fayard, 2001, p.25-26.

${ }^{28}$ DERRIDA, Jacques. Força de Lei. Trad. Leila Perrone-Moisés. São Paulo: Martins Fontes, 2007, p.24-25.

${ }^{29}$ NIETZSCHE, Friedrich. Genealogia da moral: uma polêmica. Trad. Paulo César de Souza. São Paulo: Companhia das Letras, 2009.

${ }^{30}$ ESLABÃO, Daniel da Rosa. Nietzsche e o contratualismo. I Congresso Internacional de Filosofia Moral e Política. Pelotas, 2009. Disponível em: < http://cifmp.ufpel.edu.br/anais/1/cdrom/mesas/mesa7/03.pdf>. Acesso em: 21.set.2017, p.1.

${ }^{31}$ NIETZSCHE, op cit., p.69.
} 
mais detalhada das transformações da humanidade desde seu estado natural até o nosso tempo, calcado em outros fundamentos que nada têm a ver com o pacto de vontades: houve a domesticação das pulsões humanas e da introspecção do espírito de liberdade, em decorrência da vida em sociedade, origem da má consciência e das patologias psíquicas no mesmo arrimo que nos apresenta Freud ${ }^{32}$.

Nietzsche descobre, por meio de um processo de humanização que se inicia com a memória, que comunidades baseadas em uma organização gentílica mais dotada para a guerra e com maior poder de organização têm a capacidade de se apropriarem das mais fracas, dominando-as e estabelecendo os contornos do que se poderia dizer ser uma sociedade ${ }^{33}$.

De fato, de acordo com Nietzsche, os primeiros acontecimentos em que se começa a exigir que o bicho-homem se torne confiável são as relações pessoais de troca em uma relação entre credor e devedor (Schuld). Quando a relação obrigacional não é cumprida, pela primeira vez, a violência é usada como auxiliar para fazer do homem um animal confiável ${ }^{34}$. Cria-se uma memória (mnemotécnica) por meio do castigo de que se devem cumprir suas promessas. "Aos poucos, essas relações de direito pessoal, a partir das noções de promessa, obrigação, contrato, troca, débito e direito começam a se transpor para as relações políticas em que a comunidade também estabelece uma relação de credor com seus membros devedores" ${ }^{35}$. Então surge o "Estado", ainda em uma forma rudimentar. Ele aparece a partir do uso da força de determinados homens que impõem a outros suas normas e suas regras de acordo com sua própria vontade e quem não as segue é banido da proteção da comunidade ${ }^{36}$. Além disso, "sob a pressão dessa forma primitiva de "Estado", a violência que antes seria externada contra o semelhante passa a ser internalizada, formando assim a consciência (Gewissen)" ${ }^{37}$ e criando um sentimento de culpa

32 ESLABÃO, op. cit., p.3-4.

33 CARNIO, Henrique Garbellini. Direito e Antropologia: reflexões sobre a origem do Direito a partir de Kelsen e Nietzsche. São Paulo: Saraiva, 2013, p. 173.

34 CAMARGO, Gustavo Arantes. Relações entre justiça e moral no pensamento de Nietzsche. Revista Estudos Nietzsche. v. 2. Curitiba, 2011, p.79-97. Disponível em: < http://www2.pucpr.br/reol/index.php/ESTUDOSNIETZSCHE?dd1 $=6057 \& d d 99=$ pdf $>$ Acesso em: 01.out.2017, p.92-93.

35 Ibidem, p. 94.

36 Ibidem, p. 95.

${ }^{37}$ ITAPARICA, André Luís Mota. Sobre a gênese da consciência moral em Nietzsche e Freud. Cadernos Nietzsche. v. 30. São Paulo, 2012, p.13-32. Disponível em: < http:// gen.fflch.usp.br/sites/gen.fflch.usp.br/files/u41/ artigo1.pdf $>$. Acesso em: 27.out.2017, p.17. 
("engendrador do projeto civilizatório") ${ }^{38}$.

Da mesma forma que Nietzsche, Kelsen também é contra a hipótese do contrato social em dar origem à sociedade, "pois esta não emerge da tautologia do acordo de vontades entre idealizados sujeitos de iguais direitos, mas das relações de conquista e poder" ${ }^{39}$. Da mesma forma, ambos discordam de que o homem primitivo é um homem no estado da natureza, pois ele não é um homem natural, mas social ${ }^{40}$.

Estudando a psique e a formação das comunidades primitivas ${ }^{41}$, Kelsen constata que as formas mais primevas de Estado surgem da atuação de comunidades primitivas conquistadoras e não de um contrato social ${ }^{42}$. Ademais, a proposta de Kelsen considera que a regra fundamental da ordem social primitiva é o princípio da retribuição (e não o da causalidade, fruto da evolução do pensamento humano), que domina por completo a consciência inteiramente social do homem primitivo ${ }^{43}$. "A retribuição é a imputação da recompensa ao mérito, da penitência ao pecado, da pena ao ilícito que representa a sua responsabilidade moral ou jurídica e encontra seu ponto final" ${ }^{44}$. Portanto, para Kelsen a própria definição de homem livre só se pode ter com base em uma ordem normativa onde este está inserido ${ }^{45}$.

Parece lógico que todos esses autores entendem que "a partir de uma abordagem genealógica permite-se a desmistificação metafísica do conceito de justiça ao apresentá-lo como fruto de um processo histórico de transformação do próprio homem" ${ }^{46}$ e não de um mito de um contrato social. Esta noção ficará mais aclarada no próximo item.

\section{NOÇÃO DE DIREITO COMO RELAÇÃO DE PODER E FORÇA}

\footnotetext{
${ }^{38}$ VIARO, Renee Volpato; VALORE, Luciana Albanese. Da Moral Nietzschiana ao Mal-Estar Freudiano: Algumas Aproximações e Decorrências Éticas. Estilos da Clínica (USP-Impresso). v. 17. São Paulo, 2012, p.373-395. Disponível em: < https://www.revistas.usp.br/estic/article/view/49656/53759 > . Acesso em: 19.set.2017, p.391.

39 CARNIO, op. cit., p. 173.

${ }^{40}$ CARNIO, 2013, loc. cit., p. 173.

${ }^{41}$ KELSEN, Hans. Sociedade y naturaleza: una investigación sociologica. Trad.de Jaime Perriaux. Buenos Aires: De Palma, 1945.

${ }^{42}$ CARNIO, 2013, op. cit., p. 173.

43 Ibidem, p. 40.

${ }^{44}$ Ibidem, p.46.

${ }^{45}$ Idem,

${ }^{46}$ CAMARGO, Gustavo Arantes. Relações entre justiça e moral no pensamento de Nietzsche. Revista Estudos Nietzsche. v. 2. Curitiba, 2011, p.79-97. Disponível em: <http://www2.pucpr.br/reol/index.php/ESTUDOSNIETZSCHE?dd1 $=6057 \& d d 99=$ pdf $>$ Acesso em: 01.out.2017, p. 79.
} 
Conforme Reale ${ }^{47}$, há um processo de valoração das normas pela necessidade e é nas relações sociais que aparecem esse valor, uma vez que o desejo e o medo são elementos pulsionais que movem o homem. Por meio de um movimento cognitivo, a sociedade funcionaliza a fantasia produtora do mundo criando uma fição jurídica: a norma. Portanto, o direito per se é uma ficção criada pela fantasia produtora da humanidade. Ao mesmo tempo, é poder e retribuição, já que não se separa direito da própria vida: a normatização da vida e do próprio desejo é a própria normatização que compõe a noção de direito como hoje se compreende.

De fato, por meio da análise histórica do processo de formação da civilização, conforme já descrito anteriormente, observa-se que a obrigação (obligatio) assim como o próprio direito são na realidade uma concretização do mundo civilizatório. A própria origem da força normativa é a socialização pela forma mais primitiva de se obrigar, ou seja, por um ato de violência. É por meio da retribuição a partir do vínculo de débito-crédito (relação jurídica obrigacional) que houve o processo de integração da humanidade e se iniciou o que se denomina civilização.

A grande questão que surge é qual é o contorno do direito. Mas, analisando o processo de formação histórica, percebe-se que o próprio direito é esse contorno. Nesse sentido, Carnio e Guerra Filho asseveram que "[...] se pode propor uma concepção do direito como uma forma, cujo conteúdo seria o poder, por ser onde o direito obtém sustentação, e que a ele imporia seus contornos, moldando-o para melhor e mais eficazmente ser exercido" ${ }^{48}$.

Realmente, o direito encerra em si o seu próprio limite, já que é a sociedade que delimita os limites legais (Bildung, usando a expressão kelseneana) de acordo com a sua necessidade e seus interesses. O direito é um contorno uma vez que tem que lidar com o desafio do devir. Há um processo de "desterritorialização do pensamento" inerente nesse jogo de poder. Observando-se o direito na gênese da formação cultural da humanidade, percebe-se que o direito é dito pela sociedade, assim como seus limites, e, nesse processo, tem origem ao que Nietzsche reconhece como má-consciência. De fato, é por meio do fundamento de autoridade que o direito determina o que fazer ou não e isso torna o homem ressentido. Portanto, de acordo com Carnio e Guerra Filho, "o resultado dessa escalada de direitos e

\footnotetext{
$\overline{47}$ REALE, Miguel. Lições preliminares de direito. ed.27. São Paulo: Saraiva, 2002, p.26.

${ }^{48}$ CARNIO, Henrique Garbellini; GUERRA FILHO, Willis Santiago. Teoria política do Direito: a expansão política do Direito. ed. 2. São Paulo: Revista dos Tribunais, 2013, p.115.
} 
desejos insatisfeitos é a produção de violência na tentativa de satisfazê-los, com reações violentas por parte dos que querem continuar gozando do que já possuem e buscando mais, sempre mais, e ainda mais, infinitamente" ${ }^{49}$.

Também existe um Totem de que no âmbito da sociedade tem que se viver em "paz" e de que o Estado, como detentor do monopólio da força institucionalizada, é o responsável por meio da jurisdição em trazer esta paz. Contudo, parte-se do pressuposto de que é o próprio Estado, em especial, por meio do direito, como poder e força, que estabelece o próprio conceito de paz, ainda mais que ao mesmo tempo em que é responsável por guardar o conflito, ele mesmo estabelece a relação de conflito por meio da sua normatização. Portanto, há um verdadeiro paradoxo: litiga-se em nome da paz, ou seja, usa-se o poder, a violência e a força contra a própria violência em nome de uma paz supostamente a ser estabelecida.

Nesse contexto, é salutar que se explicite que as críticas anteriormente citadas de Freud, Nietzsche e Kelsen ao contrato social de Rousseau tem algo em comum: o fato de que as relações sociais são de dominação e de poder e não de contrato social, portanto uma negação da existência de um contrato social préestabelecido. A sociedade não é fruto de um contrato, mas de uma relação de poder (uma espécie de "contrato de adesão").

Outrossim, para Kelsen, não há contratualismo, mas criam-se hipóteses para viver. A proposição, portanto, é hipotética e o conceito de liberdade é definido a partir da lei. Já para Nietzsche, a racionalidade jurídica é uma violência simbólica, portanto, não existe a melhor decisão possível porque o que há, é uma relação de dominação e poder. A comunidade cria o princípio a ser aplicado por meio do senso comunitário, isto é, uma vez que é ela quem manda. Nesse ponto, a própria noção de castigo proposto pela comunidade introjeta a ideia de procedimentos, de forma que o que se discute é a forma e não o conteúdo em si.

Também Freud lida com a ideia de resistência aos instrumentos anímicos dos povos primitivos, mas revela que a herança totêmica é passada de geração a geração por meio do inconsciente. De fato, as relações sociais ocorrem, no início, pela dominação via violência bruta ou pela apoiada no intelecto, de forma que ao longo do processo civilizatório tal violência se estende ao direito ou à lei ${ }^{50}$.

Não obstante, nesse interregno, há um processo de transferência da violência de um indivíduo para a de uma comunidade, onde cada indivíduo abre mão

\footnotetext{
${ }_{49}$ Ibidem, p. 116.

${ }^{50}$ CARNIO, 2013, loc. cit., p.123.
} 
de sua liberdade pessoal de usar força para fins violentos, cabendo à comunidade fazer respeitar as leis e executar atos legais de violência ${ }^{51}$. Tal fato proporciona um verdadeiro vínculo entre seus membros, ou seja, estabelece-se um elo emocional entre os membros de uma comunidade por meio de uma violência institucionalizada 52.

Conforme foi visto, quando se pensa em contrato social se está umbilicalmente se referindo na busca da paz, na passagem do estado da natureza para o estado civil. Mas, a paz que se entende é a que é estabelecida na perspectiva de quem domina, uma vez que é uma ilusão acreditar que todos se encontram em um estado de igualdade. Ademais, há um preenchimento da fundação mítica da autoridade da lei por uma ilusão de uma suposta paz estabelecida pela noção de direito no processo civilizatório por meio de um acordo voluntário de vontades e não com um prolongamento do uso da força e da própria coerção, por meio da instituição das leis, inibindo-se o instinto selvagem do homem. Instinto esse que constantemente se volta contra o próprio homem quando há, principalmente, uma inibição anímica e que dá origem à má-consciência e ao conflito interno existente no próprio homem.

É relevante nessa toada que se assevere que essa suposta verdade (relativa) que a jurisdição tenta estabelecer por meio da busca da pacificação social se origina do próprio conflito, isto é, conforme a tensão acontece, a verdade tende para um lado ou para o outro. Tal assertiva é coadunada pelo melhor balizamento proposto por Nietzsche ao afirmar que não existem fatos morais, mas interpretação moral dos fatos. Portanto, a menos que se adote uma postura baseada na metafísica (o que na religião se trata de um dogma), só se consegue chegar à verdade nessa noção de direito, formada ao longo do processo civilizatório, por meio do conflito.

Ato contínuo, o que define o ser humano são os limites da linguagem e a própria relação de soberania. Há uma violência simbólica quando por meio de um ato de soberania o Estado define internamente a lógica da racionalidade do delito. Ademais, o próprio Poder Constituinte faz uso da violência simbólica, na medida em que, sob uma suposta resposta à necessidade e aos problemas que afligem a comunidade (sentido originário do conceito de política), determina o direito, que muitas vezes não corresponde aos desejos da sociedade: trata-se de uma ficção teórica, cuja sustentação não é outra senão razões sentimentais.

\footnotetext{
${ }^{51}$ Idem.

52 Idem.
} 
O próprio tabu dos selvagens, tão propalado na teoria freudiana, não se encontra distante de nós e, por mais que se busque de forma ilusória marcar uma suposta evolução da civilização em relação aos povos primitivos, as tradicionais proibições morais, a que muitas vezes o homem moderno de forma inconsciente obedece, remetem-no aos instintos mais primitivos que continua ainda latente na humanidade. Uma prova disso é a própria ambivalência de pensamento em relação ao tabu que no fundo esconde algo que no inconsciente foi bloqueado, reprimido (recalque) e constantemente leva o ser humano à tentação de infringi-lo (desejo e medo).

Nesse arrimo, a origem do direito do ponto de vista da psique está nos tabus com essa ambivalência de pensamento: desejo e proibição/medo, uma vez que há constante tentativa de normatizar desejos devido ao tabu na busca de uma segurança jurídica, supostamente tentando romper uma forma de pensamento que nos aproximaria de um estado da pré-história: rejeição aos desejos existentes no ser humano. Portanto, não faz mais sentido uma visão metafísica na gênese do direito como se houvesse algo pressuposto como a elaboração de um suposto contrato social.

De fato, o direito surge, criado pela sociedade, a partir da ambivalência do pensamento e variação do sentimento. "A criação do Direito está muito relacionada e muito pressionada pela realidade vivencial (experiencial/existencial) que a sociedade presencia, as questões processuais se estruturam em modelos e atitudes utilitaristas" ${ }^{53}$.

A própria configuração de institutos jurídicos é determinada pela visão de mundo ou mundividência (Weltanschauung) subjacente ao ordenamento jurídico ${ }^{54}$.

Da mesma forma, a Justiça é metafísica, é o que se define e como o Poder Judiciário vai se pronunciar. Portanto, por formação histórica, em que a lógica/ estrutura do direito guarda uma dimensão retributiva, de imputação (não de causalidade), a noção de direito necessariamente é uma relação de poder, força e de dominação: uma extensão do interior do ser humano.

\section{CONCLUSÃO}

\footnotetext{
53 CARNIO, Henrique Garbellini. Direito e ideologia: o Direito como fenômeno ideológico. Revista Eletrônica Acadêmica de Direito Panóptica. v.3. Vitória, 2009, p.95-107. Disponível em: < http:// www.panoptica.org/ seer/index.php/op/article/view/Op_4.3_2009_95-107>. Acesso em: 19.set.2017, p.95.

${ }^{54}$ GUERRA FILHO, Willis Santiago; CARNIO, Henrique Garbellini. Teoria da ciência jurídica. ed.2. São Paulo: Saraiva, 2009, p.135.
} 
A realidade complexa em que se vive é marcada por uma lógica científica e formal que tenta ilusoriamente esconder os instintos anímicos mais primitivos. Ademais, o próprio direito é uma ficção utilizada pela sociedade para lidar com a condição existencial e de marcar um posicionamento de como o homem deve encarar o mundo. Portanto, a concepção de norma está no próprio homem.

Assim, chegou-se à conclusão, a partir da análise ao longo deste artigo, que como criação humana, o direito é fruto de um processo civilizatório marcado pela barbárie e pelo castigo, portanto por critérios totalitários. Ademais, a noção de direito é o que promove o processo civilizatório e é uma relação de poder que vai contra a psique e que, usada de forma incorreta, pode nos levar à barbárie e ao castigo. Portanto, não faz mais sentido uma visão metafísica na gênese do direito como tradicionalmente se defende a partir da teoria do contrato social de Rousseau: a noção de direito no processo civilizatório é marcada pela autoridade, assim como, na legalidade, há o risco latente da tirania e do totalitarismo.

A nosso ver, a reflexão proposta revela uma constatação indiscutível: na atualidade, somos parte de uma sociedade hedonista incapaz de viver autenticamente o sofrimento ou o tédio. Sofremos da impossibilidade de sofrer.

Nos trilhos da história, a humanização da natureza e a humanização da sociedade são construídas pelo fato de que obedecer às leis da natureza é a melhor forma de dominá-la (Bacon) e que o conhecimento científico não é o resultado de uma explicação, mas o domínio da natureza interna e externa (Descartes), ou seja, a questão principal que entre saber e poder não existe uma diferenciação, o que importa é a fuga obstinada do medo. Tudo isto ratificado pelos maduros frutos do esclarecimento que, em Kant, verifica-se como o tempo da maturidade coincide com o progresso da técnica e da ciência.

A grande questão é que nem pela ciência vamos obter uma satisfação integral para a dissipação de todo o mistério. Não é por acaso que no iluminismo encontrase um otimismo fundamentado, a ideia composta da crença, da fé de que o racional dominaria o exterior e o interior, em outras palavras, garantiria a fuga do medo.

Neste espeque, o desenvolvimento da história do ocidente, desde a iluminação, foi uma espécie de revelação de que este otimismo é um artigo de fé, crença. Tal realidade está visível nos diversos episódios históricos de reversão deste otimismo no seu contrário, ou seja, na incapacidade de resolver os macroproblemas, os homens geram problemas ainda maiores, proporcionando formas cada vez mais 
atrozes de barbárie no cometimento da vida.

Todo esse processo da pré-civilização à civilização atual nos relega a atávica percepção de que somos bem treinados a temer e o temer é uma de nossas forças motivacionais mais fortes. ${ }^{55}$

No fundo, tudo não passa de que a raiz de nosso medo advém de nossa relação com o tempo, ou seja, com a nossa própria morte ${ }^{56}$. Enquanto o homem é incapaz de assumir a finitude de forma positiva acaba inventando todas as formas de consolo, religião e metafísica. O medo que nos resta, ainda, talvez seja, sobretudo, em face dos atuais acontecimentos vivenciados em sociedade, e por uma lógica de imunização que consome paradoxalmente as relações humanas em todos os sentidos. Ademais, mesmo na não manutenção de figuras de transcendência, tornamo-nos responsáveis por nós mesmos de tal forma que tudo isto identifica minimamente que a relação do homem com o tempo e com a finitude precisa ser repensada.

A aposta aqui é a do escancaramento desta realidade para que se possa refletir desde o início sobre a possibilidade de se restaurar no homem sua relação com o passado e, nesse processo de resgate, verificar novos horizontes de possibilidades, no caso, utilizando o direito como um possível participante da discussão.

Genealogicamente, o homem é um fruto bem elaborado da perplexidade de sua própria condição existencial; já é tempo de se avançar para uma compreensão que nos projete para fora do ambiente de uma ilusão medrosa, sendo este, talvez, o primeiro passo a se dar para repensar as formas de vida que encontram no direito, em sua relação imediata com a vida, uma estrutura que orbita desde a concepção de uma legalidade espiritual do homem até uma legalidade prática das formas de vida, cujo instrumento principal é o direito e o exercício da violência.

\footnotetext{
55 No fundo, não há que se demonizar o temor, pois se aposta aqui que é desta situação de penúria do homem que se engendra também a forma de superação deste medo contida na ideia de coragem.

${ }^{56}$ Uma interessante referência filosófica, ambientada em Heidegger, sobre este tema pode ser encontrada no pensamento de Giorgio Agamben, começando com uma frase do filósofo alemão: " $<<$ A relação essencial entre morte e linguagem surge como num relâmpago, mas permanece impensada $>>$. [...] Na tradição da filosofia ocidental, com efeito, o homem figura como mortal e, ao mesmo tempo, como o falante. Ele é o animal que possui a $<<$ faculdade $>>$ da linguagem [...] e o animal que possui a faculdade da $<<$ morte $>>$ ". AGAMBEN, 2006, p. 9-10. O texto de Heidegger sobre o assunto se chama a Essência da linguagem (Unterwegs zur Sprache) e faz parte de uma coletânea denominada A caminho da linguagem. No original o texto de Heidegger sobre o tema indicado: "Mortais são aqueles que podem fazer a experiência da morte como morte. $\mathrm{O}$ animal não é capaz dessa experiência. $\mathrm{O}$ animal também não sabe falar. A relação essencial entre a morte e a linguagem lampeja, não obstante ainda de maneira impensada. Essa relação pode, contudo, nos dar um aceno para o modo em que a essência da linguagem nos intima e alcança e, com isso, nos sustenta, se é que a morte faz parte do que nos intima. Admitindo-se que o encaminhamento que sustenta os quatro campos de mundo na proximidade própria de seu encontro face a face repouse na saga do dizer, então é também a saga do dizer que confere o que designamos com a palavrinha "é", assim correspondendo-lhe. Em sua saga, o dizer concede o "é" na liberdade clara e ao mesmo tempo velada de sua possibilidade de ser pensada". HEIDEGGER, 2003, p. 170-171.
} 


\section{REFERÊNCIAS}

ABRÃO, Rosa Maria Zaia Borges. Justiça como Ordem: O Contrato Social e a análise crítica da realização da justiça e da igualdade na modernidade. Revista Direito \& Justiça. v.33. n.2. Porto Alegre, 2007, p.211-230. Disponível em: <http:// revistaseletronicas.pucrs.br/ojs/index.php/fadir/article/viewFile/2917/2206> . Acesso em: 01.nov.2017.

AGAMBEN, Giorgio. A linguagem e a morte: um seminário sobre o lugar da negatividade. Tradução de Henrique Burigo. Belo Horizonte: Ed. da UFMG, 2006.

ALVES, João Lopes. A Noção de Contrato Social nos Modernos e em Rawls. Revista Razão e Justiça - Filosofia: Publicação Periódica da Sociedade Portuguesa de Filosofia. v.4. n.1/2. Lisboa, Portugal, 1990, p. 52-104. Disponível em: < http://cful. fc.ul.pt/biblioteca/online/pdf/jalves/razaojustica.pdf > . Acesso em 01.nov.2017.

ALVES, Denise Maria; ÁLVARO, Alex Leandro Teixeira. Indivíduo, sociedade e a formação da subjetividade. Revista Científica Eletrônica de Psicologia, v. 4. n.7, 2006. Disponível em: < http://faef.revista.inf.br/imagens_arquivos/arquivos destaque/SmLVAfpoA7IA5bQ_2013-5-10-15-55-47.pdf > . Acesso em: 01.out.2017.

ALVES, Diany Mary Falcão, Nietzsche e a domesticação do animal homem. Revista Lampejo, Fortaleza, n. 4. nov. 2013, p. 15-26. Disponível em: < http://revistalampejo. org/edicoes/edicao-4/artigos/Artigo2_Diany\%20Mary\%2015\%20a\%2026.pdf>. Acesso em: 12. out. 2017.

AMARAL, Mônica Guimarães Teixeira do. A ruptura do pacto social no pensamento de Sade. Revista Trans/Form/Ação. v.15, p.65-83, 1992. Disponível em: < http:// www.scielo.br/pdf/trans/v15/v15a04.pdf> . Acesso em: 01.out.2017.

CAMARGO, Gustavo Arantes. Relações entre justiça e moral no pensamento de Nietzsche. Revista Estudos Nietzsche, v. 2, p.79-97, 2011. Disponível em: <http:// www2.pucpr.br/reol/index.php/ESTUDOSNIETZSCHE?dd1 $=6057 \& d d 99=$ pdf $>$ Ac esso em: 01. out. 2017.

CARNIO, Henrique Garbellini. Kelsen e Nietzsche: aproximações do pensamento 
sobre a gênese do processo de formação do direito. Dissertação (Mestrado) Pontifícia Universidade Católica da São Paulo (PUC-SP), São Paulo, 2008.

CARNIO, Henrique Garbellini. Direito e ideologia: o Direito como fenômeno ideológico. Revista Eletrônica Acadêmica de Direito Panóptica, v. 3, p.95-107, 2009. Disponível em: < http:// www.panoptica.org/seer/index.php/op/article/view/ Op_4.3_2009_95-107>. Acesso em: 19. set. 2017.

CARNIO, Henrique Garbellini. A gênese do direito entre Kelsen e Nietzsche. Revista Nomos, Fortaleza, v. 29, n. 2, p. 39-58, 2009. Disponível em: <http:// www. periodicos.ufc.br/nomos/article/download/6412/4651>. Acesso em: 19. set. 2017.

CARNIO, Henrique Garbellini. Direito e Antropologia: reflexões sobre a origem do Direito a partir de Kelsen e Nietzsche. São Paulo: Saraiva, 2013.

CARNIO, Henrique Garbellini; GUERRA FILHO, Willis Santiago. Teoria política do Direito: a expansão política do Direito. 2. ed. São Paulo: Revista dos Tribunais, 2013.

CARNIO, Henrique Garbellini. Rudolf von Jhering e a genealogia da ética: o devir histórico como determinante da procedência do sentimento jurídico. Revista História e Cultura. v.4, n. 3, p. 101-117, 2015. Disponível em: < http://ojs.franca. unesp.br/index.php/historiaecultura/article/download/1694/1551 > . Acesso em: 25. set. 2017.

CARNIO, Henrique Garbellini; ABBOUD, Georges; OLIVEIRA, Rafael Tomaz de. Introdução à teoria e à filosofia do Direito. 3. ed. São Paulo: Revista dos Tribunais, 2015.

COSTA, Célio Juvenal. Reflexões sobre a relação indivíduo $\mathrm{x}$ civilização na sociedade atual. Cadernos de Pesquisa em Educação PPGE-UFES. v. 38, p. 89100, 2013. Disponível em: <http:// www.periodicos.ufes.br/educacao/article/ download/7894/5602 > . Acesso em: 25. set. 2017.

DAUD, Rafael Rocha. Freud versus o contratualismo. Revista Ciência e Cultura. v. 1, p. 46-49, 2015.

DERRIDA, Jacques. Força de Lei. Trad. Leila Perrone-Moisés. São Paulo: Martins 
Fontes, 2007.

ESLABÃO, Daniel da Rosa. Nietzsche e o contratualismo. I Congresso Internacional de Filosofia Moral e Política. Pelotas, 2009. Disponível em: < http://cifmp.ufpel.edu. br/anais/1/cdrom/mesas/mesa7/03.pdf > . Acesso em: 21. set. 2017.

FREUD, Sigmund. Totem e tabu. E.S.B. XIII. Rio de Janeiro: Imago, 1978.

FREUD, Sigmund. Psicologia das massas e análise do eu. E.S.B. XVIII. Rio de Janeiro: Imago, 1978.

FREUD, Sigmund. O mal-estar na civilização. E.S.B. XXI. Rio de Janeiro: Imago, 1978.

FREUD, Sigmund. Por que a guerra?, E.S.B. XXII. Rio de Janeiro: Imago, 1978.

GAMA, Pedro Alexandre Magalhães de Saldanha da. Sobre a origem psicossomática da moral na obra de Freud "Totem e Tabu". Revista Afreudite, v. 1, n. 2, p.119149, 2005. Disponível em: < http://recil.ulusofona.pt/bitstream/handle/10437/49/ pedro_gama.pdf?sequence $=1>$. Acesso em: 05.out.2017.

GIACOIA JUNIOR, Oswaldo. Estado, democracia e sujeito de direito: para uma crítica da política contemporânea. Revista Argumenta-UENP, n. 21, p.11-23, 2014. Disponível em: <http://seer.uenp.edu.br/index.php/argumenta/article/ download/573/pdf_74>. Acesso em: 10.out.2017.

GLIKSMAN, Selmo. A ética do sobre-humano. Tese de doutorado da Pontifícia Universidade Católica do Rio de Janeiro (PUC-RJ). Rio de Janeiro, 2005, p.126-172.

GUERRA FILHO, Willis Santiago; CARNIO, Henrique Garbellini. Teoria da ciência jurídica. 2. ed. São Paulo: Saraiva, 2009.

HARDT, Lúcia Schneider. Rousseau e Nietzsche: de como a ideia de natureza estabelece o devir. Cadernos de Ética e Filosofia Política (USP), v. 21. p. $207-$ 218, 2012. Disponível em: <http:// https://www.revistas.usp.br/cefp/article/ viewFile/56562/59618 > . Acesso em: 21. set. 2017. 
HATAB, Lawrence J. Genealogia da moral de Nietzsche: uma introdução. Trad. Nancy Juozapavicius. São Paulo: Madras, 2010.

HEIDEGGER, Martin. A caminho da linguagem. Petrópolis: Vozes, 2003.

ITAPARICA, André Luís Mota. Sobre a gênese da consciência moral em Nietzsche e Freud. Cadernos Nietzsche. v. 30, p.13-32, 2012. Disponível em: < http:// gen.fflch. usp.br/sites/gen.fflch.usp.br/files/u41/artigo1.pdf > . Acesso em: 27.out.2017.

KELSEN, Hans. Sociedade y naturaleza: una investigación sociologica. Trad.de Jaime Perriaux. Buenos Aires: De Palma, 1945.

LEGENDRE, Pierre. De la societé comme Texte: Linéaments d'une Anthropologie Dogmatique. Paris: Fayard, 2001.

LEOPOLDI, José Sávio. Rousseau- estado de natureza, o "bom selvagem" e as sociedades indígenas. Revista Alceu. PUC-RJ, v.2, n. 4, p.158-172, 2002. Disponível em: <http://revistaalceu.com.puc-rio.br/media/alceu_n4_Leopoldi.pdf $>$. Acesso em: 20. out. 2017.

MARANHÃO, Bernardo Costa Couto de Albuquerque. Força de lei e fundamento da autoridade em Freud. XVIII Encontro Nacional do CONPEDI. 2009, p.3304-3319. Disponível em: <http://www.publicadireito.com.br/conpedi/anais/36/02_1108. pdf $>$. Acesso em: 20. set. 2017.

MARTON, Scarlett Zerbetto. Nietzsche e a crítica da democracia. Revista Dissertatio de Filosofia (UFPel). v. 33, p.17-33, 2001. Disponível em: < http:// > Acesso em: 23. set. 2017.

MONTEIRO, Tássia Lima Fernandes; AZEREDO, Vânia Dutra de. A Justiça como evolução do instinto de vingança: a convicção moral do Direito versus a convicção do ressentimento. In: ENCONTRO DE PESQUISA NA GRADUAÇÃO EM FILOSOFIA DA UNICAMP, 16., Campinas. Anais eletrônicos... Campinas, 2013. Disponível em: <http://www.puc-campinas.edu.br/websist/Rep/Sic08/ Resumo/2013821_10379_621824264_resIC-.pdf > . Acesso em: 20. set. 2017.

NIETZSCHE, Friedrich. Genealogia da moral: uma polêmica. Trad. Paulo César de 
Souza. São Paulo: Companhia das Letras, 2009.

PANDOLFO, Alexandre Costi. Atualidade da crítica à guerra. Revista Cultura e Fé, Porto Alegre, v. 36, p. 269-274, 2013.

PHILIPPI, Jeanine Nicolazzi. A natureza da violência - uma abordagem crítica. Seqüência: Estudos Jurídicos e Políticos, Florianópolis, v. 17. n. 33, p. 68-77, 1996. Disponível em: <http://periodicos.ufsc.br/index.php/sequencia/article/ download/15739/14252>. Acesso em: 10.out.2017.

PREVIDE, Renato Maso. A ilusão da Justiça por Kelsen. CONGRESSO NACIONAL DO CONPEDI, 24., Anais eletrônicos... Belo Horizonte: UFMG/FUMEC/Dom Helder Câmara, 2015, p. 27-52. Disponível em: < https://www.conpedi.org.br/ publicacoes/66fsl345/x20b90e4/8jh87462syn6c0N7.pdf > . Acesso em: 15.out.2017.

REALE, Miguel. Lições preliminares de direito. 27. ed. São Paulo: Saraiva, 2002.

ROSA, Roberto Sávio. Nietzsche e as razões da culpa. Especiaria - Cadernos de Ciências Humanas, Ilhéus, Bahia, v. 13, n. 24, p. 35-50, jan.jun. 2013. Disponível em: <http://periodicos.uesc.br/index.php/especiaria/article/download/694/654>. Acesso em: 21.set.2017.

ROUSSEAU, Jean-Jacques. Do Contrato Social. Trad. Lourdes Santos Machado. São Paulo: Nova Cultural, 1997.

SIEMENS, Herman. Nietzsche e a sociofisiologia do eu. Cadernos Nietzsche (online), São Paulo, v. 37, n. 1, p. 185-218, 2016. Disponível em: < http://www. scielo.br/pdf/cniet/v37n1/2316-8242-cniet-37-01-00185.pdf $>$. Acesso em: 21. set. 2017.

SILVA, Enio Moraes. O Estado Democrático de Direito. Revista de Informação Legislativa, Brasília, v. 42, n. 167, p. 213-229, jul./set. 2005. Disponível em: < http:// www2.senado.leg.br/bdsf/bitstream/handle/id/794/R167-13.pdf $>$. Acesso em: 01.nov. 2017.

SOUSA, Mauro Araujo de. Nietzsche e a Genealogia da Moral: uma obra-chave no pensamento nietzschiano. São Paulo: Zagodoni, 2014. 
STREVA, Juliana Moreira. Jean-Jacques Rousseau e o existencialismo: uma análise acerca do afeto, da potencialidade humana e da angústia de acordo com Rousseau, Sartre e Nietzsche. Revista (Online) Aurora (PUCSP), São Paulo, v. 8, p. 5-22, 2015. Disponível em: < https://revistas.pucsp.br/index.php/aurora/article/ download/23923/18884> . Acesso em: 01. nov. 2017.

VIARO, Renee Volpato; VALORE, Luciana Albanese. Da Moral Nietzschiana ao MalEstar Freudiano: Algumas Aproximações e Decorrências Éticas. Estilos da Clínica (USP-Impresso), São Paulo, v. 17, p. 373-395, 2012. Disponível em: < https://www. revistas.usp.br/estic/article/view/49656/53759> . Acesso em: 19. set. 2017.

VIESENTINER, Jorge Luiz. Algumas reflexões sobre a crítica de Nietzsche a Rousseau. In: COLÓQUIO ROUSSEAU: ORIGENS, 2., 2005. Anais eletrônicos... Campinas: IFCH-Unicamp, 2005. Anais do Disponível em: < http://www.unicamp. br/ jmarques/gip/AnaisColoquio2005/cd-pag-texto-31.htm >. Acesso em: 19. set. 2017.

VILALBA, Hélio Garone. O contrato social de Jean-Jacques Rousseau: uma análise para além dos conceitos. Revista eletrônica Filogênese, Marília, v. 6, n. 2, p. 6376, 2013. Disponível em: < http://www.marilia.unesp.br/Home/RevistasEletronicas/ FILOGENESE/heliovilalba.pdf> . Acesso em: 19. set. 2017.

Recebido em: 01 de fevereiro de 2018 Aceito em: 24 de julbo de 2018 